\title{
Econometría, teoría económica y el economista
}

\author{
Luis Mejia M. \\ Matemático economista
}

\section{RESUMEN}

La Ciencia de la Economía tiene por objeto el estudio de cómo y por qué se relacionan entre sí las variables económicas. La econometría tiene por objeto medir esas relaciones y utilizarlas para hacer predicciones.

Palabras clave: Teoría económica, variables, parámetros, estimación.

\begin{abstract}
Economic Science, Aims to study and how they relate to each other because the economic variables. The econometrics is intended to measure these relationships and use them to be predictions.
\end{abstract}




\section{Luis Mejia M.}

Al comenzar nuestro estudio de la Teoría de la Empresa, y el proceso de distribución de recursos en una economía de mercado, es importante examinar la metodología fundamental utilizada por los economistas profesionales. Esta metodología es la que se usa en todos los análisis científicos. En cualquier ciencia, natural o social, en la que no es posible una experimentación de laboratorio se originan ciertas dificultades. Pero, contrariamente a lo que algunos creen, la posibilidad de utilizar el laboratorio no es una base válida para distinguir entre las ciencias naturales y sociales. El rasgo distintivo de cualquier ciencia reside en el tema que informa su contenido, no en los métodos de estudio de este material.

El procedimiento fundamental utilizado por los economistas en su esfuerzo por ampliar nuestra comprensión del mundo en la descripción de cómo se relacionan entre sí dos variables. Por su puesto a los economistas les interesa saber qué sucede en el sector comercial cuando se toma alguna acción en el sector monetario y financiero, o qué sucede en el sector de consumidores cuando hay una rebaja en los impuestos. Deseamos conocer no solo lo que sucede, sino también la intensidad del impacto de tales acontecimientos. La investigación econométrica está estructurada para contestar a estas preguntas.

El interés en analizar y entender la estructura de la economía nacional sigue siendo de importancia capital. Así, por ejemplo: ¿cómo influye en la inversión el tipo de interés? La econometría se ocupa de medir esas relaciones causales, de mostrar cómo funciona la economía o de hacer predicciones acerca del futuro. Así, una estimación de hasta qué punto la inversión depende del tipo de interés arrojará luz sobre la eficacia de las política monetaria. Análogamente, una estimación de cómo depende de la renta el gasto de consumo es necesario para predecir el resultado de una reducción fiscal en relación con el fomento del empleo.

En economía, como cualquier ciencia social, todo tiende hasta cierto punto, a depender de todo. Así, si tratamos de explicar una variable económica como el consumo $(\mathrm{C})$, de reconocer que depende de la renta $(\mathrm{Y})$, del patrimonio $(\mathrm{A})$, y de gran número de otras variables, es decir:

$$
\mathrm{C}=\mathrm{a}+\mathrm{bY}+\mathrm{CA}+\ldots+\mathrm{e}
$$




\section{Econometría, Teoría Económica y el Economista}

Representando los puntos, las demás variables y siendo el residuo no explicado, el término error. Si prescindimos de momentos de las demás variables, el problema estadístico consiste en utilizar las observaciones sobre $C$, Y y $A$ para estimar la estructura de esa ecuación, es decir, para estimar los parámetros a, b y c.

Pero antes de recoger datos sobre $C, Y$ y A para el análisis estadístico, podemos preguntarnos: ¿No debiera esta ecuación rellenarse con toda la lista de las demás variables que causan algún efecto en el consumo? La respuesta es: No necesariamente. Hay dos buenas razones para simplificar haciendo que sea muy breve la lista. La primera es que cuantas más variables se incluyen, tanto más larga es la ecuación; por lo que es posible que no contemos con observaciones suficientes para estimarla. Pero aún sin ser grave este problema de estimación, hay buenas razones para mantener sencillas las relaciones con el fin de que resulten manejables desde el punto de vista matemático y de evitar una confusión sin salida en los detalles.

Antes que la estimación estadística, la teoría económica representa un papel importante en la simplificación de las ecuaciones, esto es, en la especificación de las variables que, como Y y A, son las más relevantes para la determinación de $C$, y de los que son menos relevantes. Las ventajas de la simplificación matemática sobrepasan en valor a la ligera pérdida de exactitud.

No obstante, debe tenerse siempre presente las inexactitudes de este tipo de simplificación. En ciertos casos pueden ser muy importantes. El examen de un error en una relación económica puede ser importante por esa misma razón. Si es sustancial, las cuestiones pertinentes son las siguientes: ¿Cómo explicar ese error? ¿Se ha emitido algo importante?

En algunos casos, la teoría económica proporciona una especificación más clara que en otros. Por una parte, al explicar la demanda de automóviles, la Teoría Económica señala claramente que debe incluirse una variable -precio-; ahora bien, ¿debe incluirse asimismo una variable que represente el gasto en publicidad del sector automovilístico? En este caso son menos claras las pautas teóricas. ¿Es importante la publicidad como factor de las ventas totales de automóviles o simplemente sirve para reasignar las ventas entre las distintas empresas? 


\section{Luis Mejia M.}

Como son muchas las cuestiones teóricas que la ciencia de la economía todavía no ha resuelto (y otras que, quizá por su naturaleza, nunca podrán resolverse plenamente), raras veces puede la teoría económica ofrecernos una especificación tan firme y clara de las variables como la que nos gustaría poseer. En consecuencia, la econometría es útil no solo para medir las relaciones conocidas -es decir, para estimar b en la ecuación (1)-, sino también para determinar si realmente existen ciertas relaciones.

Así, por ejemplo, ¿̇es cierto que la variable patrimonio de (1) afecta realmente al consumo? Técnicamente, ¿̇puede rechazarse la hipótesis de que $\mathrm{C}$ es nula? Otra función de la Econometría consiste en confirmar o rechazar una relación que quizá haya sido sugerida, no por el razonamiento teórico, sino por la observación de los datos. Así, por ejemplo, un economista que trabaje en el censo de la manufactura puede encontrar que por una razón, no inmediatamente evidente, dos variables tienden a aumentar o disminuir conjuntamente (lo mismo que hace muchos años los médicos observaron que el hábito de fumar y el cáncer de pulmón solían darse juntos). En tal caso, las técnicas estadísticas pueden utilizarse para confirmar esa asociación; después pueden plantearse preguntas como: ¿Por qué? o ¿̇ignifica esto algo?

En la ciencia económica, en la teoría de la empresa y en todas las ciencias sociales, una variable como el consumo viene con frecuencia determinada por un sistema de ecuaciones, más bien que por una sola ecuación. En otras palabras, la ecuación (1) no es suficiente por sí sola para explicar cómo se relacionan el consumo y la renta. Es cierto que (1) indica cómo depende el consumo de la renta. Pero también sabemos que la renta depende del consumo según la conocida relación:

$$
\mathrm{Y}=\mathrm{C}+\mathrm{I}
$$

Esta relación afirma simplemente que la renta es, por definición, la suma del gasto de consumo y del gasto de inversión. Juntas las ecuaciones (1) y (2), proporcionan el ejemplo más sencillo del sistema de ecuaciones simultáneas o modelo económico. Las ecuaciones de un modelo económico pertenecen a una de estas dos categorías: las que hay que estimar y las que no hay que estimar.

El valor de un modelo está relacionado directamente con el significado de los problemas que se propone resolver y con la calidad de las respuestas que aporta. 


\section{Econometría, Teoría Económica y el Economista}

Al estar tan centralizada la teoría y la estimación, todo economista debiera contar con una buena preparación en ambas ciencias.

\section{GLOSARIO}

Impuestos. La imposición de cobros por parte del gobierno sobre las personas o la propiedad con el propósito de recabar ingresos.

Política monetaria. Control de la cantidad de dinero en la economía con vista a fomentar la producción y el empleo con bajas tasas de inflación.

Estimación. Valor específico observado de un estimador.

Interés. Precio que se paga por el uso del dinero.

Inversión. Aportación de recursos que se destinan a adquirir nueva maquinaria, vivienda, empresas o estructuras agrícolas y existencias para obtener un beneficio futuro.

\section{BIBLIOGRAFÍA}

Barbancho, Alfonso. Complementos de Econometría. Edit. Ariel, 1973.

Gujarati, Remodar. Econometría Básica. Edit. McGraw-Hill, 1997.

Maddala G.S. Econometría. Edit. McGraw-Hill, 1996.

Pindyck, Robert S. Econometría. Modelos y Pronósticos. Ed. McGraw-Hill, 2001. 